\title{
Qualification and needs for self-development of supporting staff in Medical Education Centers
}

\author{
Manavika Punnan ${ }^{1}$, Natapol Supanatsetakul', Wallee Satayasai ${ }^{3}$, \\ Rajin Arora ${ }^{4}$, Supasit Pannarunothai $i^{5}$
}

\begin{abstract}
The Collaborative Project to Increase Rural Doctor Production (CPIRD) of Ministry of Public Health Thailand makes use of a number of supporting staff in facilitating medical teachers delivering clinical teaching at Medical Education Centers (MECs). This study aimed to explore the needs of selfdevelopment of supporting staffs in MECs by the postal questionnaire. The result found that the academic qualifications were diverse and their needs for self-development in medical education were high in all aspects. The survey could be useful for effective individual development plan..
\end{abstract}

Keywords: need analysis, staff development, supporting staff, medical education center

\section{Introduction}

The MECs founded by hospitals under the affiliation with CPIRD, is responsible for providing clinical experiences based on the curriculum provisioned by the undergraduates' universities (Office of CPIRD, 2008). In these hospitals, regarded as doctor-producing institutes, are expected to play roles not only in health services but also in medical education (Arora \& Kaimok, 2005). For supportive staffs who work closely with medical instructors are regarded as an important part in these hospitals where medical instructors assume a number of other roles as mentioned earlier. Consequently, they are expected to have insights and knowledge in the aspects of medical education as well. Assessing needs of self-development of the supportive staff should therefore provide a great

\footnotetext{
1. Medical Education Postgraduate, Faculty of Medicine, Naresuan University, Phisanulok, Thailand

2. MD, Ph.D., Department of Pathology and Forensic

Medicine, Faculty of Medicine, Naresuan University,

Phisanulok, Thailand

${ }^{3}$ Associate Professor, MD, Vice Dean Academic Affairs

Faculty of Medicine, Thammasat University, Bangkok,

Thailand

4. MD, Obstetrics and Gynecology Sector, Lumpang Hospital, Thailand

5. Professor, MD, Ph.D., Dean Faculty of Medicine,

Naresuan University, Phisanulok, Thailand

Corresponding Author:

Manavika Punnan, Medical Education Center,

Queen Savang Vadhana Memorial Hospital,

Sriracha, Chonburi, Thailand 20110

Tel: 006638320200 ext.1444

Email:p.manavika@gmail.com
}

advantage in outlining an accurate and effective plan on the human resource development. Moreover, some basic information unprecedentedly explored by any other surveys should benefit the standardization of positions and obligations of such staff in the future.

\section{Methods}

The study was conducted in 2009. The sample was 136 individuals selected from 21 MECs. A constructed questionnaire was conducted by the researcher and the content validity was approved by three experts. A five-level Likert's scale was used to assess level of needs. In addition, reliability of the questionnaire was verified by tryouts with 40 supportive staffs in MECs from four universities. Conbrach's alpha coefficient of the entire questionnaire was 0.92 . The information obtained was analyzed by one way analysis of variance, t-test and Scheffe's method for adjusting significance levels.

\section{Results}

There were $74.3 \%$ replied from 20 out of 21 MECs. The qualifications of the response were diverse and substantiated the aforementioned statement that only a fraction was trained for medical education. Regarding to the needs of self-development, the respondents reported average overall score at $4.10 \pm 0.86$ (mean \pm standard deviation) out of 5 scores. The needs of self-development were further divided into three aspects. The most highly ranked aspects were shown in Table 1. 
Table 1: Needs of self-development of the respondents

\begin{tabular}{|c|c|c|}
\hline \multirow{2}{*}{ Needs for self-development } & \multicolumn{2}{|c|}{ Score } \\
\hline & Mean & SD \\
\hline Overall & 4.10 & 0.86 \\
\hline 1. Education quality assurance & 4.18 & 0.77 \\
\hline 2. Class arrangement $\left({ }^{*} \mid\right)$ & 4.17 & 0.79 \\
\hline 3. Assessment and evaluation $\left({ }^{*} I I\right)$ & 4.12 & 0.83 \\
\hline 4. Education-related researches & 4.12 & 0.84 \\
\hline 5. Curriculum development & 4.12 & 0.81 \\
\hline 6. Education-related technologies $\left({ }^{*} \mid \mathrm{II}\right)$ & 3.90 & 1.10 \\
\hline *I. Class arrangement & 4.16 & 0.82 \\
\hline 1. Use of course syllabus or course outline & 4.24 & 0.80 \\
\hline 2. Large-group teaching & 4.16 & 0.81 \\
\hline 3. Clinical teaching & 4.15 & 0.82 \\
\hline 4. Small-group teaching & 4.14 & 0.81 \\
\hline 5. Problem-based learning & 4.13 & 0.85 \\
\hline *II. Assessment and evaluation & 4.12 & 0.83 \\
\hline 1. Analysis of multiple-choice examination & 4.15 & 0.80 \\
\hline 2. Use of statistics in determining grades & 4.14 & 0.81 \\
\hline 3. Interpretation of examination quality assessment & 4.13 & 0.80 \\
\hline 4. Analysis of Rating Scale or Rubrics score & 4.13 & 0.80 \\
\hline 5. Analysis of clinical skill examination & 4.12 & 0.87 \\
\hline 6. Analysis of written-answer examination & 4.10 & 0.87 \\
\hline 7. Use of examination blueprint & 4.10 & 0.84 \\
\hline 8. Analysis of portfolio & 4.09 & 0.85 \\
\hline *III. Education-related technologies & 3.86 & 1.09 \\
\hline 1. Web Based Instruction & 4.00 & 0.99 \\
\hline 2. CAI: Computer Assisted Instruction & 3.97 & 1.00 \\
\hline 3. Using Microsoft Office PowerPoint & 3.81 & 1.11 \\
\hline 4. Using Internet Explorer & 3.81 & 1.13 \\
\hline 5. Using Microsoft Office Excel & 3.79 & 1.13 \\
\hline 6. Using Microsoft Office Word & 3.77 & 1.15 \\
\hline
\end{tabular}


The statistically significant differences were 05 . There was no statistically significant differences in needs of self-development among the respondents with different ages, experiences in medical education working, fields in which they graduated and experiences in medical education training.

\section{Discussion}

This study indicated that the academic qualifications were diverse. Only a fraction of the staff was trained for medical education. The results were congruent with a survey on the subject which was conducted in March 2009. Prior to this research, opinions were gathered from 49 executives of MECs by means of questionnaires and interviews. The first two most significant problems are issues of management on macroscopic scale. They pointed out that prioritized problem of inexperienced supportive staff as third rank because of insufficiency of staff and inadequate funds for development of such staff, in order of increasing significance.

Also, the results from this study confirmed the information of the office of CPIRD (2008) that most of staff are not acquainted with medical education before work. Further investigations revealed that the majority of these staff did not graduate from the fields directly related to education. Although, there are difficulties in recruiting appropriate staff, the MEC should have policies on staff development and should be formative (World Health Organization, 2001). When compared to supportive staff employed in higher education in the civil service, their position is regarded as educators and belong to specialist's line of work with precisely a defined scope of responsibility, job description, required of the specialty qualification and competency for each level (Office of Higher Education, 2008), it contrastively raises a concern on MECs on why a similar infrastructure has not yet been implemented.

\section{Conclusion}

This research unveiled a variety of needs of self-development in the supportive staff in medical education. This result could effectively be incorporated into the process of outlining the policy and plan for the development of such staff to appropriately suit their needs. In addition, it has provided an accurate and effective plan on the human resource development. Moreover, some basic information could benefit the standardization of positions and obligations of such staff in the future.

\section{References:}

Arora, R \& Kaimok, A. (2005) Medical Education for Beginners, 1, Bangkok: Sangsau Printing.

Office of CPIRD, Ministry of Public Health (2008), The Collaborative Project to Increase Rural Doctor Production [Online] Available at: http://newcpird.org [Accessed18th June 2008].

Office of Higher Education Commission, Standards Positioning Civil Servants in Institutes [online] Available at: http://www.moph.go.th/ops/general/ knowledgedetail.php?id=110 [Accessed 18 June 2008].

World Health Organization, Regional Office for the Western Pacific (2001), WHO Guidelines for Quality Assurance of Basic Medical Education in the Western Pacific Region [Online] Available at: http://www.wpro.who.int/NR/rdonlyres/ E5F6 CEB7-312A-4A86-BBDA0A8E13F94323/0/ Guidelines_Quality_Assurance.pdf [Accessed 3 July 2011] 